\title{
TELAAH ULANG PERGERAKAN LEMPENG TEKTONIK INDO-AUSTRALIA DENGAN MENGGUNAKAN DATA GPS TAHUN 1994-2016
}

\author{
Ashar Muda Lubis ${ }^{1 *}$, Krisno Rianto Simatupang ${ }^{1}$, Edi Purwanto ${ }^{1}$ \\ ${ }^{1}$ Jurusan Fisika, Fakulas MIPA, Universitas Bengkulu, Jl. WR Supramtman, Kandang Limun, Bengkulu, 37381 \\ *e-mail: asharml@unib.ac.id
}

\begin{abstract}
ABSTRAK
Lempeng tektonik Indo-Australia merupakan salah satu lempeng tektonik utama yang terus bergerak hingga sekarang. Dimasa lalu penelitian tentang vektor pergerakannya telah dilakukan (1994-2001). Dengan banyak gempabumi yang terjadi di wilayah Sumatera pada dua dekade ini, maka perlu dilakukan penelitian re-investigasi kecepatan pergerakan lempeng tektonik Indo-Australia dengan menggunakan span data yang lebih jauh (1994-2016). Penelitian ini bertujuan untuk re-investigasi besar kecepatan dan arah pergerakan lempeng tektonik Indo-Australia dengan menggunakan data Global Positioning System (GPS). Stasiun GPS yang diamati sebanyak 4 stasiun yakni: COCO, XMIS, PERT, and DARW. Data penelitian diperoleh dari Scripts Orbit and Permanent Array Center (SOPAC). Pengolahan data menggunakan perangkat GAMIT/GLOBK 10.5. Dengan menggunakan model linear untuk menghitung vektor komponen horizontal lempeng tektonik Indo-Australia, maka hasil pergerakan pada 4 stasiun pengamatan GPS menuju ke arah timur laut dengan 69.42-72.55 $\mathrm{mm} /$ tahun. Secara umum hasil penelitian memberikan error perhitungan sangat kecil yakni $>1 \mathrm{~mm} /$ tahun. Hasil penelitan juga menunjukkan bahwa bahwa stasiun COCO mengalami peningkatan pergerak ke arah Utara-Selatan jika dibandingakan dengan penelitian sebelumnya. Peningkatan pergerakan ke arah utara ini menuju Pulau Sumatra mungkin disebabkan oleh adanya pergerakan mantle relaxation akibat gempa-gempa bumi besar pada dua dekade terakhir pada zona subduksi Sumatra.
\end{abstract}

Kata Kunci: lempeng tektonik; Indo-Australia; pergerakan GPS; timur-laut.

\section{ABSTRACT}

[Title: Re-investigation Indo-Australian plate tectonic movement using GPS data during 1994-2016] The IndoAustralian tectonic plate is one of the main tectonic plates that continues to move until now. In the past, research on its movement was carried out during 1994-2001. With many of great earthquakes occurring in Sumatra region in the past two decades, it is necessary to reestimate the speed of Indo-Australian tectonic plate using more Global Positioning System (GPS) data (1994-2016). The aim of this study is to re-investigate the speed and direction of Indo-Australian tectonic plate. Four GPS stations were used namely; COCO, XMIS, PERT, and $D A R W$. The GPS data were obtained from the SOPAC, and data processing was conducted by using GAMIT/GLOBK 10.5. By using a linear model to calculate the horizontal deformation of Indo-Australian plate tectonic, the result of movement for 4 GPS stations is 69.42$72.55 \mathrm{~mm} /$ year headed northeast direction. In general, the results give a very small error of $>1 \mathrm{~mm} /$ year. The results also show that the COCO station experienced an increasing in movement towards the North-South compared with previous studies. This increasing northward movement towards Sumatra Island may have been caused by mantle relaxation due to major earthquakes in the last two decades in the Sumatra subduction zone.

Keywords: Tectonic plate; Indo-Australian; GPS movement; northeast.

\section{PENDAHULUAN}

Lempeng Hindia-Australia bergerak ke utara menumbuk lempeng Eurasia dengan kecepatan 50$70 \mathrm{~mm} /$ tahun (Bock, dkk., (2003). Zona tumbukan dua lempeng di sepanjang Palung laut SumateraJawa-Bali-Lombok (Gibbons, dkk., 2015; Van Hinsbergen, dkk., 2018). Lempeng Australia menunjam ke busur kepulauan di sepanjang tepi kontinen dari tepian selatan timur-timur terus ke timur dan melingkar berlawanan arah jarum jam di
Lautan Banda (Zahirovic, dkk., 2015; Müller, dkk., 2019). Gerakan dari tabrakan dan pergeseran lempeng besar ini direspon oleh kepulauan Indonesia. Akibat dari pergerakkan lempeng tektonik ini, maka Indonesia berada pada daerah rawan bencana gempa bumi karena dapat menimbulkan unsur-unsur tektonik lainnya seperti sesar, patahan lokal, dan lipatan. Dari kondisi ini menjadikan wilayah Indonesia sebagai daerah 
tektonik aktif dengan tingkat sesmisitas atau kegempaan yang tinggi.

Penelitian tentang pergerakkan lempeng Indo-Australia telah dilakukan penelitian oleh Tregoning, dkk., (1998) pada stasiun (monumen) MORE di Port Moresby, Australia yang menunjukkan pergerakkan relatif sebesar $\sim 4 \pm 1$ $\mathrm{mm} /$ tahun dengan azimut $274 \pm 15^{\circ}$. Perkiraan sebelumnya tidak ada ditemukan kecepatan dengan gerak relatif yang signifikan terhadap lempeng Australia (Tregoning dkk., 1998). Perkiraan di sini berasal dari data yang jauh lebih lama (yakni $\sim 11$ tahun, yang sebelumnya $\sim 6$ tahun).

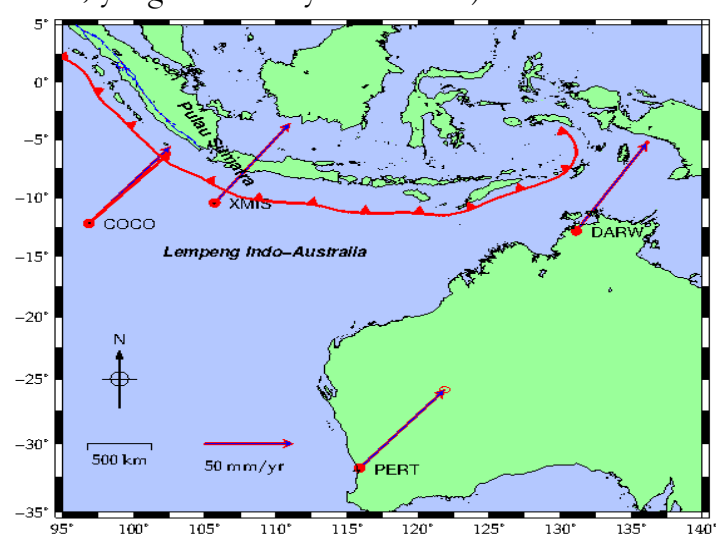

Gambar 1. Peta lempeng tektonik Indo-Australia dan vektor pergerakan hasil dari Tregoning et al., (1998) (vektor merah) selama 11 tahun, dan hasil penelitian ini (vektor biru) yang dilakukan selama 23 tahun.

Dari pengamatan Tregoning dkk., (1998) pada tahun 1994-2001 masih banyak hal yang perlu diteliti. Hal ini dikarenakan pada akhir-akhir ini banyaknya aktivitas gempa bumi di wilayah zona subduksi Sumatra yang diakibatkan dari lempeng Indo-Australia. Apabila pergerakkan lempeng tektonik Indo-Australia yang bergerak ke arah utara dan bergerak ke arah sebaliknya atau arahnya sejajar maka perlu dilakukan penelitian. Kemudian data yang diamatinya oleh Tregoning dkk., (1998) hanya 11 tahun, dan model pengamatan berupa garis linear. Sehingga dari hal tersebut masih perlu dilakukan penelitian pergerakkan lempeng tektonik dengan dengan menggunakan waktu yang lebih lama (23 tahun). Hal ini perlu dilakukan karena setelah gempa-gempa bumi besar terjadi pergerakan pada lapisan litosfer karena diinduced oleh relaksasi lapisan astenosfer. Penelitian ini bertujuan untuk melihat posisi tahunan dari lempeng Indo-Australia secara 2 dimensi, kemudian untuk mengetahui besar dan kecepatan vektor di lempeng Indo-Australia dari tahun 1994 sampai 2016 (23 tahun).

\section{METODE}

Penelitian ini mengamati pergerakan deformasi Lempeng tektonik Indo-Australia di titik pengamatan GPS stasiun COCO, XMIS, PERT, dan DARW. Sedangkan titik-titik ikatnya yaitu NTUS, BAKO, SAMP, dan TIBD yang berada pada lempeng Eurasia. Durasi data yang digunakan dari tahun 1994-2016. Data diperoleh dari website: ftp: / / garner.ucsd.edu.

Setelah penggumpulan data GPS harian, maka pengolahan dimulai dengan mengonversi data Compact RINEX menjadi data RINEX dengan bantuan TEQC (Translation, Editing, and Quality Checking). Selanjutnya data format RINEX ini dioleha dengan perangkat lunak GAMIT/GLOBK untuk mendapatkan posisi secara time series. Past prosssing pengolahan data menggunakan metode Widjajanti dkk., (2020). Hasil yang digunakan untuk analisis vektor kecepatan hanya data komponen horizontal saja yakni data arah UtaraSelatan dan Barat-Timur (2 dimensi).

Adapun cara untuk menghitung besarnya kecepatan vektor pergeseran masing-masing titik adalah dengan metode linear fit. Metode linear fitting yaitu memanfaatkan pendekatan fungsi linear yang dirumuskan dengan persamaan:

$$
y=a x+b
$$

dimana $\mathrm{x}$ adalah waktu pengamatan (tahun + Day Of Year (DOY)/365), y adalah posisi harian pada stasiun pengamatan saat waktu pengamatan. a adalah kecepatan pergerakan platektonik dan b nilai konstanta untuk posisi GPS. Nilai a dan b ditentukan berdasarkan kumpulan pengamatan berdasarkan persamaan (Marbun, dkk., 2018):

$$
\begin{aligned}
& a=\frac{\left(\sum Y_{i}\right)\left(\sum x_{i}^{2}\right)-\left(\sum x_{i}\right)\left(\sum x_{i} y_{i}\right)}{n \sum x_{i}^{2}-\left(\sum x_{i}\right)^{2}} \\
& b=\frac{n \sum x_{i} y_{i}-\left(\sum x_{i}\right)\left(\sum y_{i}\right)}{n \sum x_{i}^{2}-\left(\sum x_{i}\right)^{2}}
\end{aligned}
$$

\section{HASIL DAN PEMBAHASAN}

Pada Gambar 2 diperlihatkan data posis GPS secara time series untuk titik pengamatan stasiun COCO pada dua komponen yaitu komponen UtaraSelatan dan Barat-Timur. Masing-masing komponen dapat dilihat bahwa posisi tahunan GPS untuk komponen Utara-Selatan, bergerak sejauh $53.14 \pm$ $0.12 \mathrm{~mm} /$ tahun. Kemudian dari posisi tahunan GPS komponen Barat-Timur bergerak sejauh $45.72 \pm$ 
$0.08 \mathrm{~mm} /$ tahun (Gambar 2). Sedangkan data time series untuk posisi tahunan GPS di stasiun XMIS dapat dilihat pada Gambar 3. Untuk komponen Utara-Selatan stasiun bergerak sekitar 55.01 \pm 0.07 $\mathrm{mm} /$ tahun, sedangkan pergerakan posisi tahunan GPS untuk komponen Barat-Timur sejauh $42.36 \pm$ $0.06 \mathrm{~mm} /$ tahun (Gambar 3).

Pada Gambar 4 diperlihatkan posisi tahunan GPS pada stasiun PERT secara time series. Dapat dilihat bahwa pergerakan posisi tahunan GPS PERT untuk komponen Utara-Selatan sejauh 54.16 \pm 0.83 $\mathrm{mm} /$ tahun. Kemudian untuk pergerakan posisi tahunan GPS PERT untuk komponen Barat-Timur sejauh $47.87 \pm 1.19 \mathrm{~mm} /$ tahun. Sementara itu data time series untuk posisi tahunan GPS pada stasiun DARW diperlihatkan pada Gambar 5. Untuk komponen Utara-Selatan stasiun DARW bergerak sejauh $60.75 \pm 0.40 \mathrm{~mm} /$ tahun, sedangkan untuk komponen Barat-Timur sejauh $39.67 \pm 0.38$ $\mathrm{mm} /$ tahun.

Dari hasil penelitian ini terlihat bahwa keempat stasiun pengematan bergerak kearah timur laut diaman stasiun DAWR yang berada di Darwin memiliki pergeseran terbesar dengan kecepatan pergeseran sebesar $72.55 \mathrm{~mm} /$ tahun. Sedangkan titik pergeseran terkecil berada di titik pengamtan XMIS dengan kecepatan $69.42 \mathrm{~mm} /$ tahun. Kemudian untuk titik-titik pergeseran yang lainnya, seperti stasiun COCO sebesar $70.10 \mathrm{~mm} /$ tahun dan untuk stasiun PERT sebesar $72.28 \mathrm{~mm} /$ tahun.
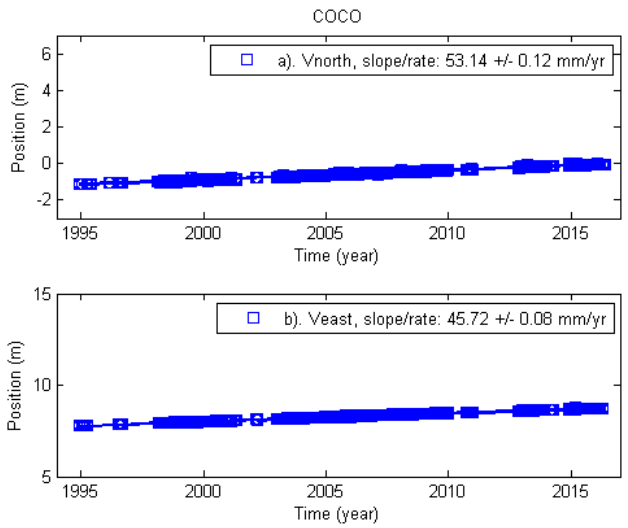

Gambar 2. Posisi pergerakan stasiun COCO untuk komponen Utara-Selatan (atas) dan komponen Barat-Timur (bawah).
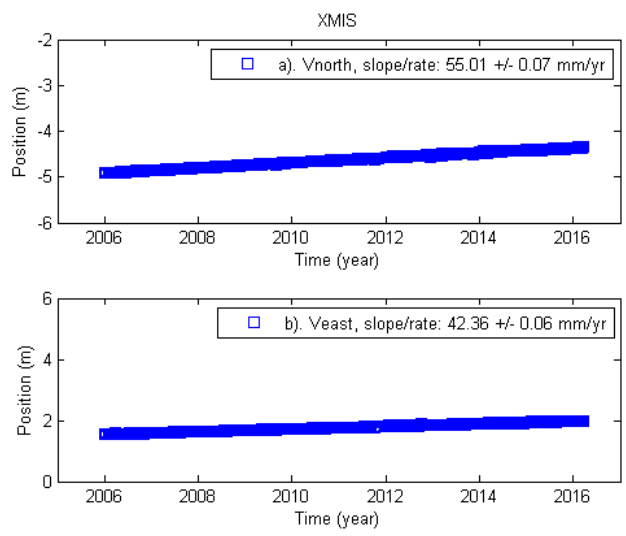

Gambar 3. Posisi pergerakan stasiun XMIS untuk komponen Utara-Selatan (atas) dan komponen Barat-Timur (bawah).
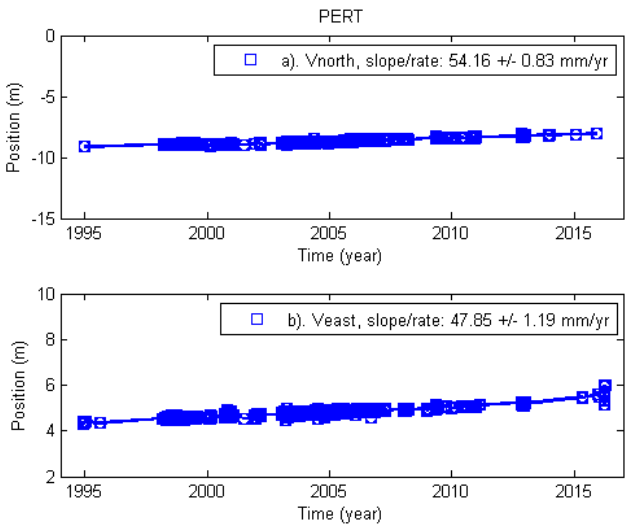

Gambar 4. Posisi pergerakan stasiun PERT untuk komponen Utara-Selatan (atas) dan komponen Barat-Timur (bawah).
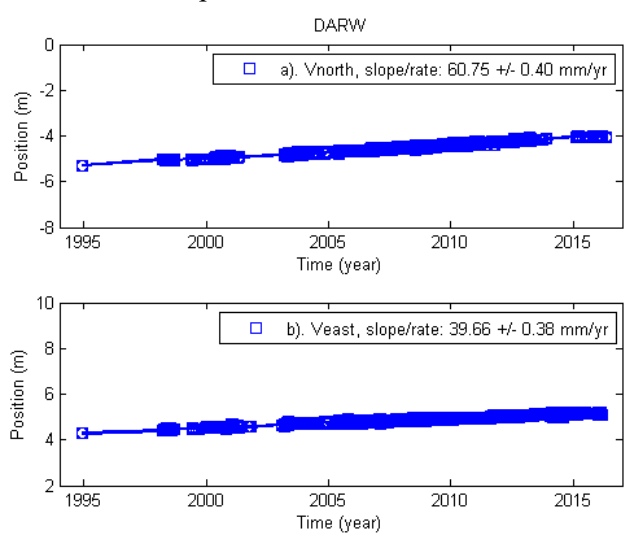

Gambar 5. Posisi pergerakan stasiun DARW untuk komponen Utara-Selatan (atas) dan komponen Barat-Timur (bawah).

Secara umum error penelitan ini sangat kecil yakni > $1 \mathrm{~mm} /$ tahun untuk komponen UtaraSelatan, bahkan untuk stasiun DARW, XMIS dan COCO kecil dari $0.5 \mathrm{~mm} /$ tahun. Sementara itu untuk komponen Barat-Timur, error perhitungan $>$ $0.4 \mathrm{~mm} /$ tahun kecuali untuk stasiun PERT yang mencapai $1.2 \mathrm{~mm} /$ tahun. Dengan demikian secara 
perhitungan hasil yang diperoleh memiliki tingkat kepercayaan yang tinggi, sehingga dapat dijadikan sebagai referensi untuk kajian lempeng tektonik khususnya untuk wilayah Sumatra.

Untuk vektor dari kecepatan pergerakan lempeng Indo-Australia secara horizontal dari titiktitik pengamatan COCO, XMIS, PERT, dan DARW dapat dilihat pada Gambar 1. Hasil vektor pergerakan yang diperoleh konsisten dengan kerangka pengerakan lempeng tektonik pada IndoAustralia dimana lempeng ini menujam sepanjang Palung laut Sumatera-Jawa-Bali-Lombok (Bock et al. 2003).

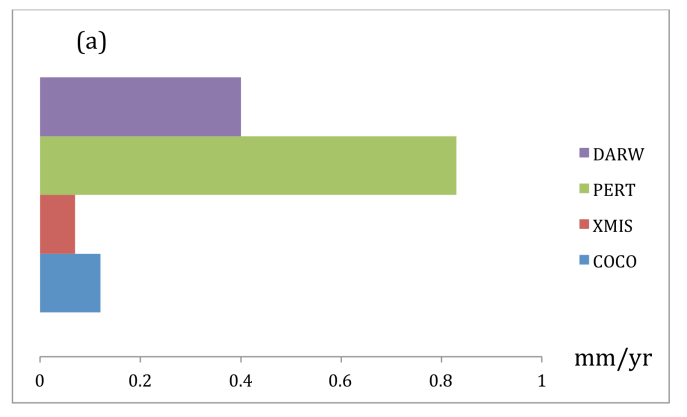

(b)

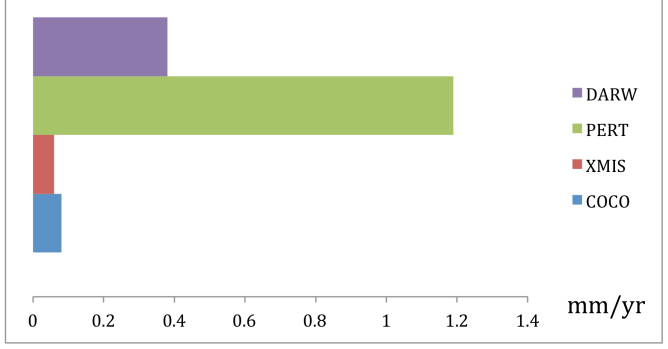

Gambar 6. Error perhitungan kecepatan lempeng Indo-Australia, (a) untuk komponen Utara-Selatan, dan (b) untuk komponen Barat-Timur.

Pada Gambar 1 diperlihatkan hasil plot vektor kecepatan pergerakan lempeng tektonik Indo-Australia. Dapat dilihat bahwa pegerakan lempeng tidak mengalami perbedaan secara signifikan pada stasiun XMIS, PERT, dan DARW bila dibandingkan dengan Tregoning dkk., (1998). Sementara itu pada stasiun COCO yang bergerak bergerak sejauh $53.14 \pm 0.12 \mathrm{~mm} /$ tahun komponen Utara-Selatan dari 23 tahun pengamatan mengalami peningkatan pergerakan pada arah yang sama dengan penelitian sebelumnya yang hanya $49.0 \mathrm{~mm} /$ tahun (Tregoning, dkk., 1998). Sementara untuk komponen Barat-Timur tidak ada perbedaan yang signifikan. Peningkatan pergerakan ke arah utara ini menuju Pulau Sumatra mungkin disebabkan oleh adanya pergerakan mantle relaxation setelah gempa- gempa bumi besar pada dua dekade terakhir pada zona subduksi Sumatra. Pergererakan seperti ini dikenal dengan post-seismik viscoelastic mantle relaxation (Rudolph, dkk., 2015).

Menurut Lubis dkk., (2013) pergerekan mantle relaxation dapat menimbulkan pergerakan secara pelan-pelan pada permukaan bumi dalam waktu yang lama setelah kejadian gempa bumi besar. Dengan demikian ada sedikit perubahan pergerakan lempeng pada stasiun yang tegak luruk terhadap sumber-sumber gempa di Sumatra. Oleh karena itu kedepan pemodelan viscoelastik kombinasi dengan pergerakan plate tektonik sangat diperlukan untuk memahami proses tumbukan pada pertemuan lempeng tektonik di wilayah Sumatra.

\section{KESIMPULAN DAN SARAN}

Dari hasil dan analisis yang telah dilakukan pada 4 stasiun titik-titik pengamatan GPS yakni pada stasiun COCO, XMIS, PERT, dan DARW dapat disimpulkan bahwa pergerakan lempeng IndoAustralia bergerak kerah timur laut dimana pergerakan terbesar terdapat pada stasiun DARW dengan kecepatan pergeseran sebesar 72.55 $\mathrm{mm} /$ tahun, sedangkan titik pergeseran terkecil adalah stasiun XMIS $69.42 \mathrm{~mm} /$ tahun. Kemudian untuk titik-titik pergeseran yang lainnya, seperti stasiun COCO bergerak sebesar $70.10 \mathrm{~mm} /$ tahun dan untuk stasiun PERT bergerak sebesar 72.28 $\mathrm{mm} /$ tahun.

Dari penelitian ini juga dapat ditarik kesimpulan bahwa stasiun COCO mengalami peningkatan pergerak ke arah Utara-Selatan jika dibandingakan dengan penelitian sebelumnya. Peningkatan pergerakan ke arah utara ini menuju Pulau Sumatra mungkin disebabkan oleh adanya pergerakan mantle relaxation akibat gempa-gempa bumi besar pada dua dekade terakhir pada zona subduksi Sumatra.

\section{UCAPAN TERIMAKASIH}

Penulis mengucapkan kepada Scripts Orbit and Permanent Array Center (SOPAC) yang dikelola oleh IGPP ( Institut of Geophysics and Planetary) Universitas California yang telah menyediakan data GPS. Ucapan terima kasih juga untuk Laboratorim Fisika, Universitas Bengkulu atas penyedian fasilitas pada penelitian.

\section{DAFTAR PUSTAKA}

Bock, Y., L. Prawirodirjo, J.F. Genrich, C.W Stevens, R. Mccaffrey, C. Surabaya, S.S.O. Puntodewo \& E. Calais. 2003. Crustal motion in Indonesia from Global Positioning 
System measurements. Journal of Geophysical Research. Vol. 108. No. B8, https: / / doi.org/10.1029/2001JB000324

Gibbons, A., Zahirovic, S., Muller, R., Whittaker, J., \& Yatheesh, V. 2015. A tectonic model reconciling evidence for the collisions between India, Eurasia and intra-oceanic arcs of the central-eastern Tethys. Gondwana Resesearch. Vol 28, 451-492, https://doi.org/10.1016/j.tecto.2018.04.0 06.

Lubis, A.M., Hashima., A., \& Sato T. 2013. Analysis of afterslip distribution following the 2007 September 12 southern Sumatra earthquake using poroelastic and viscoelastic media. Geophysical Journal International. Vol 192, 1, 1837, https://doi.org/10.1093/gji/ggs020.

Marbun, M., Sihotang, H.T., \& Nababan, M.A. 2018. Perancangan Sistem Peramalan Jumlah Wisatawan Asing. Jurnal Mantik Penusa. Vol 2 (1), 41-49.

Müller, R.D., Zahirovic, S.,Williams, S.E., Cannon,J., Seton, M., Bower, D.J., Tetley, M.G., Heine, C.H, Breton, E.L., Liu, S., Russell, H.J., Yang, T., Leonard, T., \& Gurnis, M. 2019. A global plate model including lithospheric deformation along major rifts and orogens since the Triassic. Tectonics, Vol 38, 1884-1907, https://doi.org/10.1029/2018TC005462.

Rudolph, M., Lekić, V., Lithgow-Bertelloni, C. 2015. Viscosity jump in Earth's midmantle. Science. Vol 350,1349-1352, https://doi.org/ 10.1126/science.aad1929.

Tregoning, P., Lambeck, K., Stolz, A., Morgan, P., McClusky, M.C., van der Beek, P.,
McQueen, H., Jackson, R.J., Little, R.P., Laing, A., \& Murphy, B. 1998. Estimation of current plate motions in Papua New Guinea from Global Positioning System observations. Journal of Geophysical Research. Vol 103, 12.181-12.203, https: / / doi.org/10.1029/97JB03676.

Van Hinsbergen, D.J.J., Lippert, P.C., Li, S., Huang, W., Advokaat, E.L., Spakman, W. 2018. Reconstructing Greater India: Paleogeographic, kinematic, and geodynamic perspectives. Tectonophysics, Vol 760, 69-94. https://doi.org/10.1016/j.tecto.2018.04.0 06.

Widjajanti, N., Pratama, C., Parseno, Sunantyo T.A., Heliani L.S., Ma'ruf B., Atungggal D., Letari D., Ulinnuha, H., Pinasti A., \& Ummi R.F. 2020. Present-day crustal deformation revealed active tectonics in Yogyakarta, Indonesia inferred from GPS observations, Geodesy and Geodynamics, Vol 11(2), 135142 , https://doi.org/10.1016/j.geog.2020.02.0 01 .

Zahirovic, S., Muller, R., Seton, M., \& Flament, N. 2015. Tectonic speed limits from plate kinematic reconstructions. Earth Planet Sciences Letter. Vol 418, 40-52, https://doi.org/10.1016/j.epsl.2015.02.03 7. 